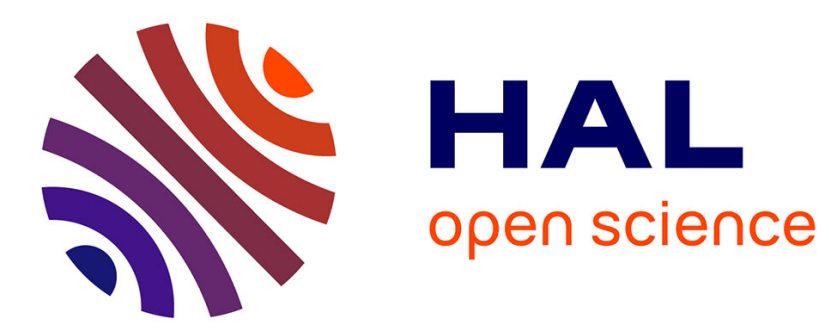

\title{
Demonstration of NO production in air plasmametallic surface interaction by broadband laser-induced fluorescence
}

D Studer, P Boubert, P Vervisch

\section{- To cite this version:}

D Studer, P Boubert, $\mathrm{P}$ Vervisch. Demonstration of NO production in air plasmametallic surface interaction by broadband laser-induced fluorescence. Journal of Physics D: Applied Physics, 2010, 43 (31), pp.315202. 10.1088/0022-3727/43/31/315202 . hal-00569664

\section{HAL Id: hal-00569664 https://hal.science/hal-00569664}

Submitted on 25 Feb 2011

HAL is a multi-disciplinary open access archive for the deposit and dissemination of scientific research documents, whether they are published or not. The documents may come from teaching and research institutions in France or abroad, or from public or private research centers.
L'archive ouverte pluridisciplinaire HAL, est destinée au dépôt et à la diffusion de documents scientifiques de niveau recherche, publiés ou non, émanant des établissements d'enseignement et de recherche français ou étrangers, des laboratoires publics ou privés. 


\title{
Demonstration of NO production in air plasma - metallic surface interaction by broadband laser-induced fluorescence
}

\author{
D Studer, $\mathbf{P}$ Boubert and $\mathbf{P}$ Vervisch \\ CORIA - UMR 6614 CNRS, Université et INSA de Rouen, 76801 Saint-Etienne du \\ Rouvray Cedex, France \\ E-mail: boubert@coria.fr
}

\begin{abstract}
This paper deals high temperature chemistry of air in interaction with a metallic surface. A subsonic air plasma is created with an inductive torch and is investigated using broadband $\mathrm{KrF}$ laser-induced fluorescence. Nitrogen monoxide fluorescence spectra are recorded in the free subsonic plasma jet as well as within the boundary layer above a stainless steel flat plate water-cooled to $300 \mathrm{~K}$. The comparison between calculated and experimental calibrated fluorescence spectra allows the determination of rotational and vibrational temperatures as well as densities of NO ground state. The results demonstrates a strong non-equilibrium between rotational and vibrational temperatures in both the free jet and the boundary layer including very close to the wall. Density determinations show that nitrogen monoxide is in chemical equilibrium on the axis of the free jet but not on its boundaries. The NO results are analyzed together with previous $\mathrm{O}_{2}$ and $\mathrm{N}_{2}$ results obtained by Raman spectrosocpy in order to explain the increasing NO densities observed within the boundary layer. The discussion highlights a double production of NO due to catalytic reactions at the wall and to the exothermic reaction $\mathrm{N}+\mathrm{O}_{2} \longrightarrow \mathrm{NO}+\mathrm{O}$ within the boundary layer following $\mathrm{O}_{2}$ recombination at the wall.
\end{abstract}

PACS numbers: $52.25 . \mathrm{Os}, 52.40 . \mathrm{Hf}, 52.50 . \mathrm{Qt}, 52.70 . \mathrm{Kz}$

\section{Introduction}

The entry or re-entry of space vehicles in planetary atmospheres remains a serious issue for aerospace engineers because of the significant heat flux and heat load encountered during the aerobraking phase. For exploration probes, low-density ablative materials such as PICA (Phenolic Impregnated Carbon Ablator) are used for the thermal protection system (TPS), but for reusable vehicles such as space shuttles, the TPS is non-ablative [1-3]. The TPS is supposed to resist to heat flux densities up to $400 \mathrm{~kW} / \mathrm{m}^{2}$ mostly caused by convection in the case of Earth re-entry. The re-entry velocity is then about $7.5 \mathrm{~km} / \mathrm{s}$ while the future lunar manned missions and Mars sample return missions will require re-entry velocities up to $15 \mathrm{~km} / \mathrm{s}$. The TPS resists because of its high specific heat, its high boiling point as well as its high emissivity at high temperature. Future 
missions, especially manned missions, will require an upgraded safety level but also an optimization of the TPS mass. This purpose should be reached through a better understanding of high temperature chemistry of air and of its interaction with TPS materials.

Atomic species (atomic nitrogen and mainly atomic oxygen) produced behind the shock wave created by high velocity in front of the space vehicle induce two phenomena when they interact with the vehicle wall: recombination with a transfer of the released energy to the wall on the one hand, and reaction with atoms of the wall to create a protection layer (passive oxidation) or to destroy the TPS (active oxidation) on the other hand. Both phenomena may be modelled by a five-step process: diffusion of reactants to the wall, associative or dissociative adsorption, chemical reaction on the wall, molecular or thermal desorption, diffusion of products away from the wall. The slowest reaction fixes the kinetics of the whole process. The adsorption and desorbtion processes being determining, weakly catalytic materials are preferred for space re-entry use. However studies concerning materials with an higher catalycity such as cooled stainless steel are very important to understand those processes. The catalytic recombination probability of stainless steel remains nevertheless far from unity [4] but much higher than the recombination coefficient of silicon carbide for example. Because of the low dissociation energy of molecular oxygen, atomic oxygen is the majority atomic species in the shock layer and its role is very important. Jumper and Seward developed a model for oxygen recombination supposing that atomic oxygen adsorbs on silicon atoms of silica [5] and reaction-cured glass [6]. A comprehensive review on this subject was written by Kovalev and Kolesnikov [7].

The role of NO was taken into account by Barbato et al. [8] in their models. NO is then produced either by exothermic reaction of atomic nitrogen with molecular oxygen or by the endothermic reaction of atomic oxygen with molecular nitrogen. We will discuss these reactions again later. Kurotaki [9] dealt with the reaction of an atom of oxygen in the gas phase with an atom of nitrogen adsorbed on the surface. Recently, Pejaković et al. [10] brought the evidence that heterogeneous production of NO on quartz is quantitatively as significant as surface recombination of nitrogen and oxygen. The energies involved in reactions that produce NO justify the interest for that molecule in the boundary layer.

Laser-induced fluorescence remains the most accurate way to get data about the ground state of the NO radical. It was used in various high enthalpy facilities using the $\gamma$ band as excitation path (mainly at $226 \mathrm{~nm}$ ) as well as the $\epsilon$ band (mainly at $193 \mathrm{~nm}$ ) [11-13] and especially for air plasma-surface interaction studies $[14,15]$. Schulz et al. [16] showed that NO could be excited near $248 \mathrm{~nm}$ using a narrow-band $\mathrm{KrF}$ exciplex laser. In spite of the possible excitation of $\mathrm{O}_{2}$ along the Schumann-Runge bands, we chose to use a broadband laser to excite simultaneously rotational levels belonging to different vibrational levels.

In order to reproduce in laboratory the conditions encountered near the boundary layer during an atmospheric entry, inductively coupled plasma torches were shown to 
present a lot of advantages though the plasma generation mode is very different from the atmospheric entry reality. This kind of plasma source is very steady and allows hours of continuous work. Because of the absence of contact between the electrode and the gas, the gas is not contaminated which is very important for chemical kinetic studies. More details about adequacy of ICP torch to test TPS materials could be found for example in $[17,18]$.

In a previous work [19], $\mathrm{N}_{2}$ and $\mathrm{O}_{2}$ ground state temperatures and densities were monitored using Spontaneous Raman Spectroscopy (SRS) in an air plasma free jet and also within a boundary layer of a flat cooled metallic plate immersed in this plasma flow. Following those first investigations, this work presents some measurements of NO characteristics obtained by broadband laser-induced fluorescence of the $\gamma$ bands in the same configurations. NO ground state temperatures and densities were derived from the comparison of experimental and calculated fluorescence spectra. After describing the experimental set-up and methodology, the hypotheses made for the calculation of fluorescence spectra are discussed and the results obtained in the free jet and in the boundary layer are described and discussed.

\section{Experimental}

\subsection{ICP wind tunnel}

Experiments were carried out in the CORIA research centre $100 \mathrm{~kW}$ inductively coupled plasma wind tunnel. The plasma generator is made up of a quartz tube that is $80 \mathrm{~mm}$ in diameter surrounded by five-turn water-cooled coils driven by a $1.7 \mathrm{MHz}$ triode oscillator. The gas injection is annular and weakly swirled $\left(10^{\circ}\right)$. The plasma is ignited with argon then switched to synthetic air ( $80 \%$ nitrogen and $20 \%$ oxygen). The test chamber $(0.5 \mathrm{~m}$ in diameter) is water-cooled and equipped with three optical access ports around. They are movable even under low pressure thanks to a dovetail joint. During this campaign, the power sent to the inductor was $42 \mathrm{~kW}$ and the mass flow rate was fixed to $2.4 \mathrm{~g} / \mathrm{s}$. Considering an efficiency coupling estimated to $50 \% \pm 10 \%$, those values correspond to a specific enthalpy close to $9 \mathrm{MJ} / \mathrm{kg}$ and a plasma jet velocity equal to $250 \mathrm{~m} / \mathrm{s}$ (so clearly subsonic in these conditions). Measurements were performed in the plasma free jet and over a metallic flat plate. This one was set parallel to the flow axis, $80 \mathrm{~mm}$ from the quartz tube exit. The plate was made of stainless steel and cooled down to $300 \mathrm{~K}$ thanks to water circulation. It was $100 \mathrm{~mm}$ large and $150 \mathrm{~mm}$ long. The leading edge was coated with mullite $\left(\mathrm{Al}_{2} \mathrm{O}_{3} / \mathrm{SiO}_{2}\right)$ on $5 \mathrm{~mm}$ long to prevent it from oxidation by atomic oxygen. Figure 1 gives a view of the plate in the plasma flow from the top and the side as well as the coordinate system in the free jet and within the boundary layer. 


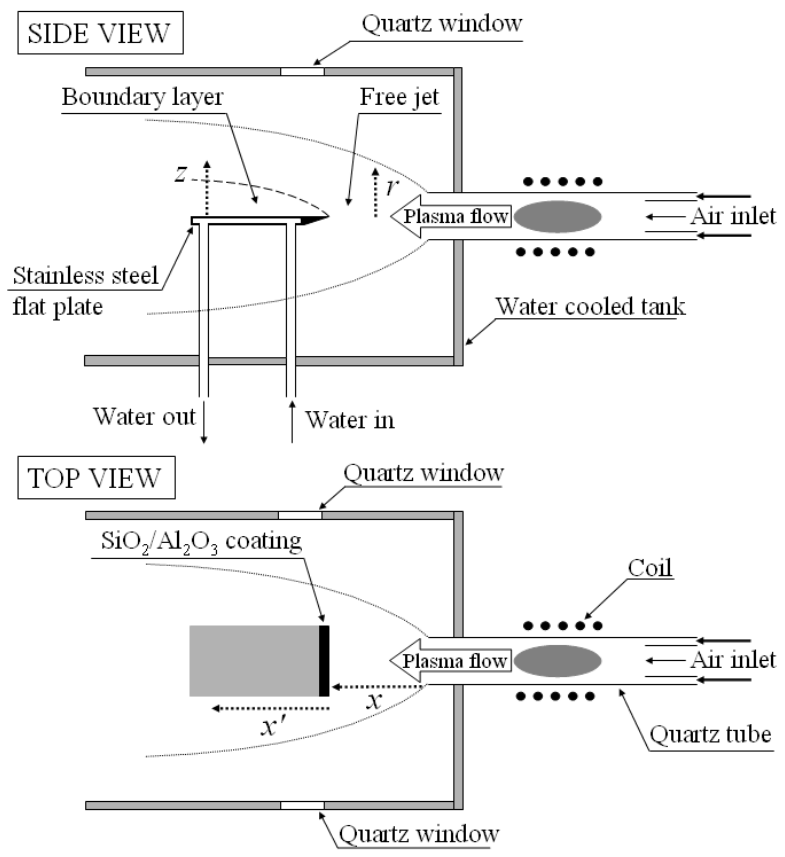

Figure 1. General arrangement of the metallic flat plate in the plasma flow

\subsection{Laser and optical set-up}

Laser-induced fluorescence used in the frame of this study consists of the absorption of coherent light by the ground state of molecules and their excitation to an electronic excited state. In the case of $\mathrm{NO}$, those electronic states are labeled $X^{2} \Pi$ and $A^{2} \Sigma^{+}$ respectively. The principle of the measurement is to collect the induced emission resulting from the de-excitation of the excited level to the ground state. The collection is made through a spectrometer in order to get spectral information.

The laser used was a broadband KrF exciplex laser (TuiLaser ExciStar M-100) providing $200 \mathrm{~mJ}$ pulses around $248.5 \mathrm{~nm}$ with a maximum frequency of $20 \mathrm{~Hz}$. This frequency is useful in order to reduce the acquisition time and to improve the signal-to-noise ratio. The fluorescence signal is especially sensitive to three laser features that are the beam shape, the spectral profile and the time evolution. As shown in figure 2, the spatial energy distribution is especially regular. This is an advantage for modelling purposes. Of course, in order to rebuild fluorescence spectra, the knowledge of the spectral distribution of the laser energy is important. The spectral profile (Figure 3) was measured through the Rayleigh scattering signal outside the wind tunnel using a spectrometer Jobin-Yvon THR1000 equipped with a $4320 \mathrm{gr} / \mathrm{mm}$ UV grating. The spectral resolution was close to $0.02 \mathrm{~nm}$. Rayleigh scattering was also used to record the time evolution of laser power. The time profile has been obtained with a Philips XP2020Q photomultiplier as well as with an intensified CCD camera. In the latter case, the ICCD camera was operated in a sequential mode using shifted gates 2 ns long every 2 ns. In spite of a lower resolution with the ICCD camera method, both time profiles 


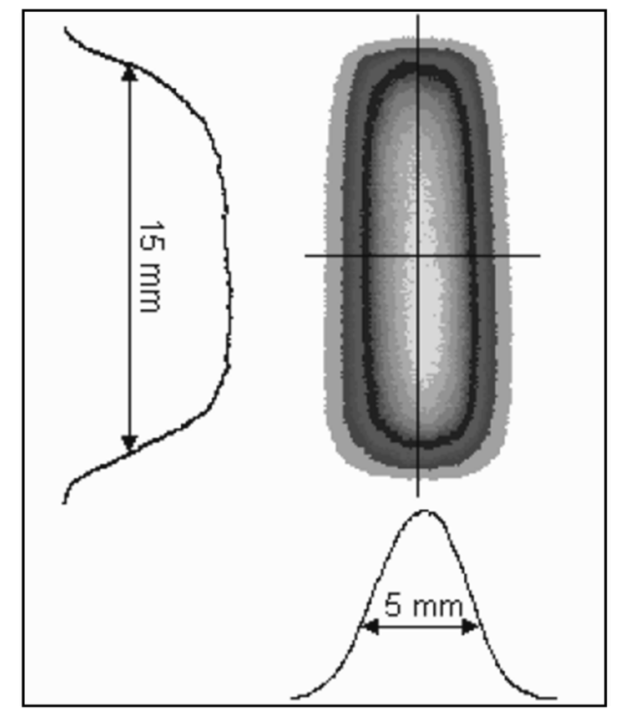

Figure 2. KrF laser spatial profiles and intensity distribution

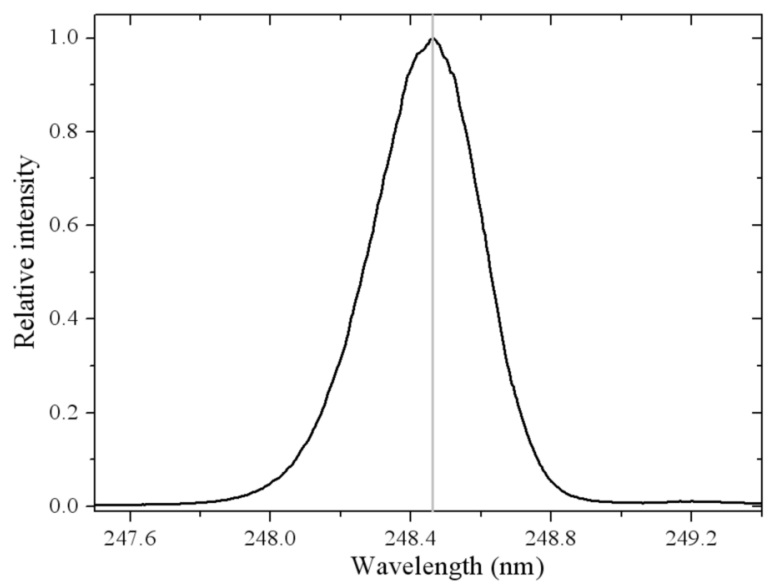

Figure 3. Spectral profile of the broadband $\mathrm{KrF}$ laser

are very similar as shown in figure 4. Further time profiles were then recorded only with the ICCD camera method. The camera was a Princeton Instrument PI-MAX with a $512 \times 512$ matrix (the pixel size is $26 \times 26 \mu \mathrm{m}$ ). Each acquisition was triggered by a TTL pulse sent by the laser beam monitor. The kind of laser used yields an especially divergent beam which drove us to use two converging lenses in afocal configuration at the exit of the laser box. The focusing lens had a focal length equal to $500 \mathrm{~mm}$ in order to keep a good geometric shape of the beam as well as a constant section at the measurement point. In such a configuration no beam divergence correction were needed. The optical set-up is shown in figure 5 .

We chose a moderate spectral resolution in order to obtain a good illumination. So a 300 $\mathrm{mm}$ spectrometer was used with a $1200 \mathrm{gr} / \mathrm{mm}$ UV grating to diffract the fluorescence light collected by a lens whose focal length was $200 \mathrm{~mm}$. In this configuration the 
Demonstration of NO production in air plasma - metallic surface interaction by broadband laser-induced.

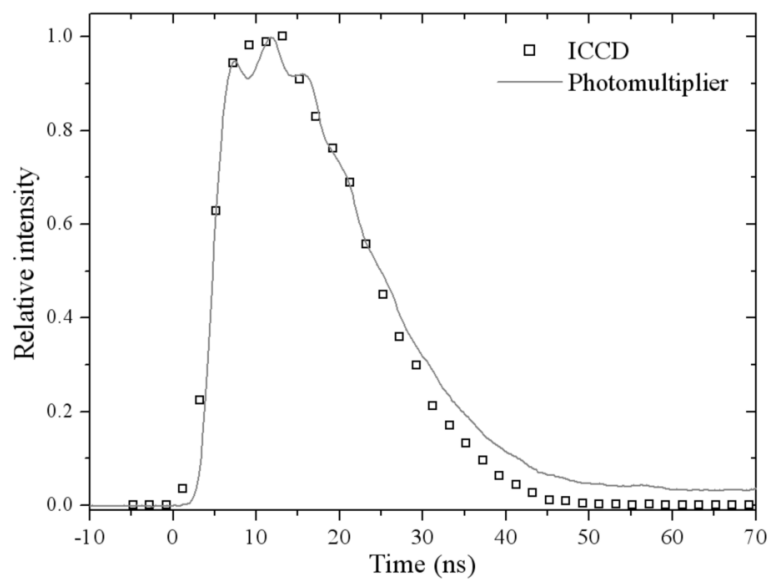

Figure 4. Time evolution of the Rayleigh scattering induced by the $\mathrm{KrF}$ laser in air measured by a photomultiplier and a gated ICCD camera

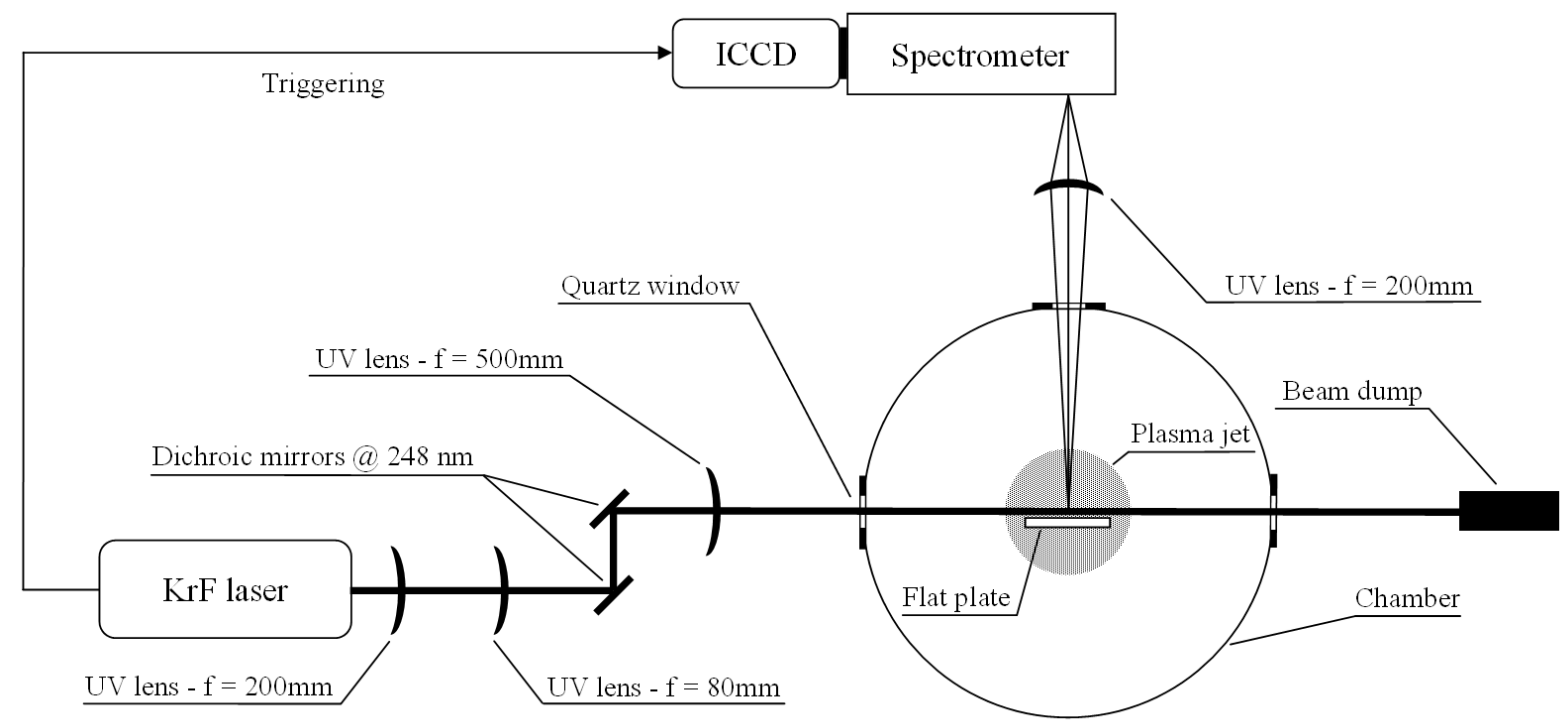

Figure 5. Optical set-up

magnification was equal to 0.43 and the recorded fluorescence signal came from a $33 \mathrm{~mm}$ long cylinder. To obtain a better spatial resolution, this length was reduced to $7 \mathrm{~mm}$ during post-processing by using only a part of CCD pixels. Considering the spectrometer entry slit width fixed to $50 \mu \mathrm{m}$, the spatial resolution in the direction of the jet was estimated to $116 \mu \mathrm{m}$ and the spectral resolution to $0.30 \mathrm{~nm}$ at $200 \mathrm{~nm}$ and $0.25 \mathrm{~nm}$ at $300 \mathrm{~nm}$. The measurement volume was then a parallelepiped $7 \mathrm{~mm}$ long (along the laser axis), $116 \mu \mathrm{m}$ wide (along the jet axis) and $0.5 \mathrm{~mm}$ high. 


\subsection{Spectrum acquisition}

Each measurement was the result of twelve software accumulations of one hundred physical accumulations (100 ns each) on the CCD. Considering the laser frequency $(20 \mathrm{~Hz})$, one measurement corresponded to an acquisition time close to one minute. The noisy background was measured before each acquisition and subtracted during the software accumulation. In order to avoid any saturation effect on the CCD, the Rayleigh scattering signal, which was more than one order of magnitude higher than the fluorescence one, should not be recorded. Moreover preliminary acquisitions had shown that the fluorescence manifolds located close to 230 and $240 \mathrm{~nm}$ respectively were especially sensitive to temperature. So the grating was set to prevent the Rayleighscattered laser beam to fall onto the CCD. The spectral range recorded was then limited to $209-241 \mathrm{~nm}$.

\subsection{Calibration}

Numerous reflections in the wind tunnel prevented to use the Rayleigh scattering signal in cold gas as calibration signal. So a deuterium lamp was used to calibrate the optical set-up. First, it was calibrated in irradiance against a tungsten ribbon lamp in a small range around $300 \mathrm{~nm}$. It was then possible to determine the energy collected by the optical set-up during one acquisition against the absolute irradiance of the lamp. Such a procedure was applied for a few measurement points corresponding to different locations in the diameter of the plasma jet on the collection optical axis. The outcome of calibration is to work with an absolute scale i.e. to quantify the radiative energy collected by one sensitive element of the CCD during the exposure time. The absolute scale allowed to derive NO densities by direct comparisons with calculated spectra.

\section{Fluorescence spectrum calculation}

To derive temperatures and densities from laser-induced fluorescence measurements, calibrated experimental spectra were compared with calculated spectra. This process needed to take into account all the phenomena occurring during the excitation and deexcitation phases such as non radiative energy transfers, to discuss the accuracy of the parameters used and to carefully describe the molecular energy structure and estimate the transition probabilities.

\subsection{Excited levels}

The spectroscopic system involved is the $\gamma$ bands of NO. The NO $\gamma$ bands are due to the rovibronic transitions between the first excited electronic state, i.e. the doublet $A^{2} \Sigma^{+}$, and the electronic ground state $X^{2} \Pi$. Concerning the upper $A^{2} \Sigma^{+}$state, the spectroscopic constants used are those from Danielak et al. [20]. For NO $X^{2} \Pi$ ground state, Amiot [21] provided accurate spectroscopic constants, high vibrational levels 
included.

The broadband excitation of NO allows a simultaneous absorption of the laser light by low rotational levels of the $X^{2} \Pi\left(\mathrm{v}^{\prime \prime}=2\right)$ state - to $A^{2} \Sigma^{+}\left(\mathrm{v}^{\prime}=0\right)$ - and by high rotational levels of the $X^{2} \Pi\left(\mathrm{v}^{\prime \prime}=3\right)$ state - also to $A^{2} \Sigma^{+}\left(\mathrm{v}^{\prime}=0\right)$. This feature is the key point of the sensitivity of fluorescence spectra to temperatures. The laser radiation was also absorbed by other vibronic transitions of $\Delta v=-2$ and $\Delta v=-3$ manifolds that were also taken into account in the calculations.

\subsection{Coupling cases}

The upper states of the NO $\gamma$ transitions are $\Sigma$ states. That means that the coupling of spin, orbital and nuclear momentum is described by Hund's case (b). Conversely, the lower electronic state is a $\Pi$ state that obeys the Hund's case $(a)$ for low rotational quantum numbers, then intermediate case, then Hund's case $(b)$ as the rotation of nuclei increases. One of the main difference is that Hund's case (b) allows more transitions and some so-called satellite lines appear for high rotational quantum numbers.

We calculated the fluorescence spectra with two models and the comparison showed some well located differences. The first model considers NO $X^{2} \Pi$ ground state as belonging to Hund's case $(b)$. The second model considers a description along Hund's case $(a)$ for low rotational quantum numbers and along Hund's case (b) for high rotational quantum numbers. The limit is classically fixed when $Y=J(J+1)$ with $J$ a quantum number linked to the total kinetic momentum (rotation and spin) and $Y$ the ratio between the spin-orbit coupling constant $A$ and the rotational constant $B$. The limiting $J$ value is 8.5 in this case. Spectra calculated with the Hund's case (b) description for all the $X^{2} \Pi$ rotational levels correctly predict the location of most lines but show some extra lines that are not present on the experimental spectra. Those extra lines are ${ }^{S} R_{21}$ and ${ }^{O} P_{12}$ lines for example at $232 \mathrm{~nm}$ (Figure 6). Conversely, the more comprehensive model, dealing with Hund's case $(a)$ for low rotational levels, leads to incorrect line locations but to intensities that are in good agreement with experiments. Finally, in spite of the high sensitivy of some parts of the calculated fluorescence spectra to the coupling case used for low rotational levels of $X^{2} \Pi$ electronic state, the influence of the coupling case on temperature measurements remains weak and does not increase significantly the error bars. Therefore, we chose the Hund's case (b) for the description of the NO ground state whatever the value of $J$ in order to be consistent with the emission spectroscopy calculations that provide satisfying agreements with experimental spectra within this coupling case.

\subsection{Transition probabilities}

We considered the transition probabilities to be the product of a rotational contribution given by the Hönl-London factors (calculated according to Kovács [22]), and a pure vibrational contribution. Differences between the three sets of vibrational transition 


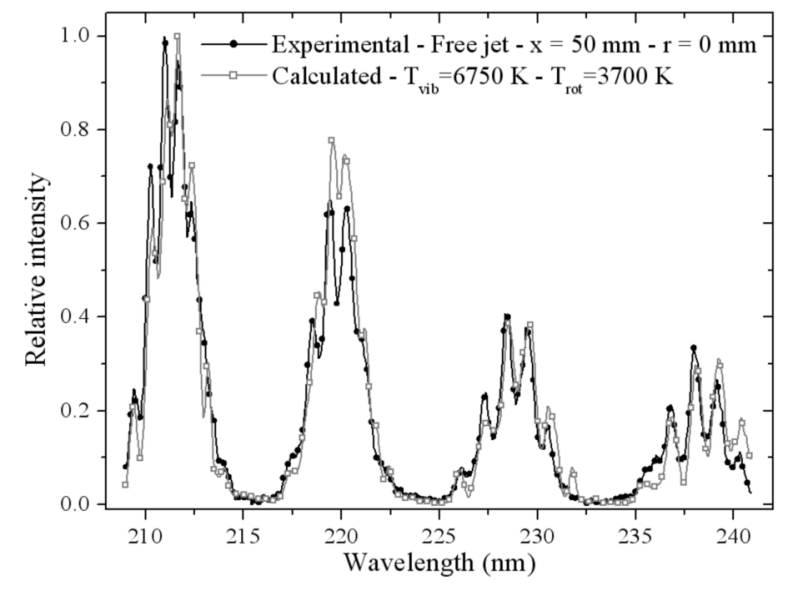

Figure 6. Example of experimental fluorescence spectrum and simulation

probabilities tested [23-25] are not negligible and fluorescence spectra are especially sensitive to such differences. Each experimental fluorescence spectrum was compared with spectra calculated with the three sets and in all cases, the values provided by Luque and Crosley [25] have given the best agreements. So, for the vibrational bands studied in this work, we do consider that those values are the best available at this time.

\subsection{Rotational and vibrational energy transfers}

In the case of fluorescence spectra, a Boltzmann distribution of rovibrational states in the upper electronic state (in our case $A^{2} \Sigma^{+}$of NO) is not appropriate. Therefore, some hypotheses had to be made in order to determine the population induced by the laser absorption.

Excitation being realized by a broadband laser, vibrational energy transfers (VET) and rotational energy transfers (RET) need not be modelled. First, because of the broadband excitation, exchanges between adjacent states are balanced. Secondly, their characteristic times are long enough not to disturb the general shape of the fluorescence spectrum. VET cross sections by $\mathrm{N}_{2}$ and NO are $0.129 \AA^{2}$ and $0.46 \AA^{2}$ respectively for transition $A^{2} \Sigma^{+}(\mathrm{v}=1 \rightarrow \mathrm{v}=0)$ [26]. Those values correspond to characteristic times equal to 4.9 and $49 \mu$ s respectively. Cattolica et al. [27] also found weak VET cross sections that may be considered as constant with the vibrational quantum number. RET cross sections were determined for few rotational numbers of $A^{2} \Sigma^{+}(\mathrm{v}=0)$ by Lee et al. [28] who shown that they do not exceed a few $\AA^{2}$ (the RET cross sections are nevertheless dependent of the rotational quantum number). Naik and Laurendeau [29] also studied RET at high pressure and concluded that they remain negligible at low laser fluences. A broadband excitation as ours corresponds to that definition. Independently of literature values for RET cross sections, our experiments confirmed their negligible influence. First, we did not observe any evolution of the fluorescence spectra during the test time (about $80 \mathrm{~ns}$ ). That means that the rotational distribution induced by the laser 
excitation remains unchanged by collisions during that duration. Secondly, we also measured the rotational temperature of the $A^{2} \Sigma^{+}$state by emission spectroscopy [30]. Those measurements demonstrated that the rotational temperature of the excited state and the rotational temperature of the ground state are different. That means that RET characteric time is even lower than aerodynamic characteristic time and then much lower than fluorescence characteristic time.

In the fluorescence calculations, photoionisation and photodissociation were found to have a really negligible influence. They were removed from the calculation to reduce the time cost.

\subsection{Quenching}

For a two-level system, the Einstein balance equation is written :

$$
\frac{d n_{u}}{d t}=n_{l} B_{l u} u_{\nu}-n_{u}\left(A_{u l}+B_{u l} u_{\nu}+Q_{u l}\right)
$$

where $\mathrm{n}_{u}$ and $\mathrm{n}_{l}$ are respectively the upper and lower population density of a transition, $\mathrm{A}_{u l}, \mathrm{~B}_{u l}$ and $\mathrm{B}_{l u}$ are Einstein coefficients, $\mathrm{Q}_{u l}$, the quenching rate and $\mathrm{u}_{\nu}$ the monochromatic energy density. The radiative lifetimes of $\mathrm{NO} A^{2} \Sigma^{+}$vibrational levels are in the range 150-220 ns. The order of magnitude of Einstein vibronic coefficients for $\operatorname{NO}(\gamma)$ is about $10^{6} \mathrm{~s}^{-1}[25]$.

If the fluorescence characteristic time is much larger than the laser characteristic time, the time evolution of the fluorescence signal has to be calculated by solving the Einstein balance equation. On the contrary, the upper population density follows the laser time evolution and a steady model is convenient. It also means that steady state models are valid only for high quenching rates. An estimate of the quenching rates may be achieved by comparison between calculation results and experimental time evolutions. Such a comparison is shown in figure 7 for a measurement made on the axis on the free jet. Because our laser temporal FWHM is close to $20 \mathrm{~ns}$, this method is useless for quenching rate values higher than $10^{10} \mathrm{~s}^{-1}$.

Albeit it is significant, the quenching rate can be estimated with a good accuracy and a value close to $2 \times 10^{9} \mathrm{~s}^{-1}$ fits well with the experimental time evolution at least in the first 30 nanoseconds of the phenomenon. After that time, another quenching rate is appropriate. Its value is about $4.5 \times 10^{7} \mathrm{~s}^{-1}$. A similar effect, though less pronounced, was already observed on the fluorescence along the NO $\epsilon$ bands and was ascribed to amplified spontaneous emission (ASE) between $D^{2} \Sigma^{+}$and $A^{2} \Sigma^{+}$states [31]. This interpretation is not valid here since there is no other electronic state between $A^{2} \Sigma^{+}$and $X^{2} \Pi$. In the present case, it is useful to notice that the slope change occurs when the laser power is no more than $20 \%$ of its maximum value. The quenching rates were systematically measured and experimental values were used in the calculation of densities. The measured values of the quenching rates are high and further investigations and explanations are needed to fully understand their origin. A comprehensive discussion about this subject will be exposed in a forthcoming paper. 


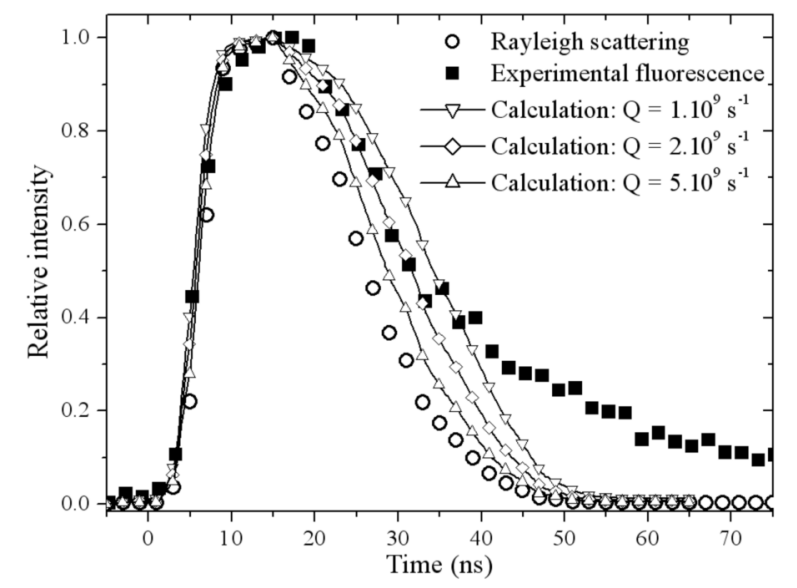

Figure 7. Measured and calculated time evolution of the fluorescence signal

The fact is that NO $A^{2} \Sigma^{+}$is depopulated to the ground state since our calculations, in which the sum of the populations of ground and excited states is constant (see next section), gives coherent results.

\subsection{Steady state hypothesis}

The spectral intensity $\left[\mathrm{W} /\left(\mathrm{cm}^{2} . \mathrm{cm}^{-1}\right)\right]$ of the $\mathrm{KrF}$ was calculated for two specific wavelengths corresponding to the maximum of power and to the excitation of high rotational levels of $\mathrm{v}^{\prime}=0 \leftarrow \mathrm{v}^{\prime \prime}=2$ band whose role is especially important in the shape of the fluorescence spectrum. It was also calculated at two times corresponding to 4 and $20 \mathrm{~ns}$ after the beginning of the laser pulse. The results are presented in table 1 for a pulse energy equal to $50 \mathrm{~mJ}$. In his book about laser diagnostics for combustion,

\begin{tabular}{cll}
\hline & \multicolumn{2}{l}{ Wavelength $(\mathrm{nm})$} \\
\cline { 2 - 3 } $\mathrm{t}(\mathrm{ns})$ & 248.0 & 248.4 \\
\hline 4 & $8 \times 10^{3}$ & $8 \times 10^{5}$ \\
\hline 20 & $4 \times 10^{4}$ & $4 \times 10^{6}$ \\
\hline
\end{tabular}

Table 1. KrF laser spectral intensity $\left[W /\left(\mathrm{cm}^{2} . \mathrm{cm}^{-1}\right)\right]$

Eckbreth [32] proposed to estimate the time to reach the steady state as a function of the laser spectral intensity and the quenching rate. His example is for $\lambda=350 \mathrm{~nm}$ and a spontaneous emission Einstein coefficient equal to $2 \times 10^{6} \mathrm{~s}^{-1}$ but it is very helpful in our conditions. Indeed, a comparison with Eckbreth's values shows that whatever the time in the laser intensity evolution and whatever the wavelength, the time to reach equilibrium remains lower than $1 \mathrm{~ns}$. A so short time means that the fluorescence regime may be considered as in a steady state in our experiments. The evolution of the each 
upper population density may then be written :

$$
n_{u}(t)=\frac{n_{N O} B_{l u} u_{\nu}(t)}{\left(B_{l u}+B_{u l}\right) u_{\nu}(t)+\sum_{i} A_{u i}+Q}
$$

In this equation the quenching rate $Q$ is assumed to be independent of vibrational and rotational quantum numbers. For a given laser energy, calculations showed that some transitions are saturated while some others are not. That means that no $a$ priori hypothesis should be made about the saturation or linearity of the excitation process. Last the monochromatic energy density was considered to be constant over the measurements volume. This hypothesis is very correct over the laser section and is acceptable along the laser axis.

\subsection{Sensitivity}

Calculated fluorescence spectra are especially sensitive to three parameters: the quenching rate, the laser energy and the value of the vibrational transition probability. This last point was already discussed above. The influence of the quenching on temperature measurements, that is on the relative shape of the spectrum, is negligible at low temperatures where only the low rotational levels of the $\mathrm{v}^{\prime}=0 \leftarrow \mathrm{v}^{\prime \prime}=2$ band are involved. Conversely at temperatures higher than $2000 \mathrm{~K}$, higher vibrational manifolds, whose importance increases in the spectrum, proves to be very sensitive to the quenching rate. The sensitivity of the density measurements on the quenching rate requires accurate determination of that parameter for each measurements points. The dependence of the fluorescence energy on the quenching rate is shown in figure 8 . There is a quite weak sensitivity of the fluorescence spectrum shape to the laser energy. The accuracy of the calorimeter allowed to know this energy at $\pm 2 \mathrm{~mJ}$. That did not add significant uncertainty on the temperature determination nor on the density determination as illustrated in figure 9. On this plot, a laser energy doubling does not induce a linear increase of the fluorescence energy. On the other hand, the critical parameter is the cross section of the laser beam and more peculiarly its dimension along axis perpendicular to the plate ( $z$ axis). That dimension was estimated to be close to $500 \mu \mathrm{m}$. This value questions the validity of measurements carried out very close to the wall where the probed volume was probably not homogeneous because of high temperature gradients. Nevertheless, no error is due to fluorescence reflections on the metallic plate: they were shown to be negligible even close to the wall.

\subsection{Derived data and uncertainties}

Vibrational and rotational temperatures were obtained by comparison between normalized experimental and calculated fluorescence spectra. Knowing the temperatures of the NO ground state, densities were deduced from the absolute fluorescence intensity. A least-square minimization process were used with two free parameters: vibrational and rotational temperatures. 


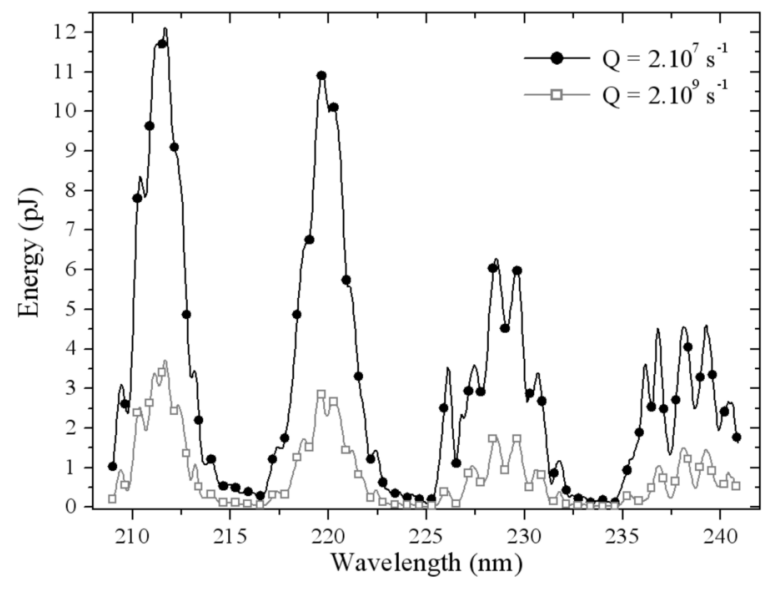

Figure 8. Dependence of calculated fluorescence spectrum on the quenching rate for $\mathrm{E}=50 \mathrm{~mJ}$ and $\mathrm{T}_{e q}=5000 \mathrm{~K}$

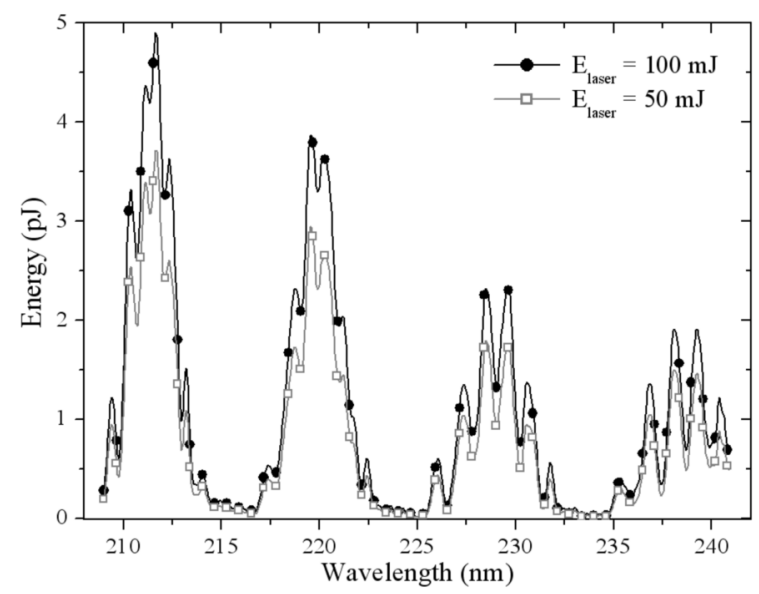

Figure 9. Dependence of calculated fluorescence spectrum on the laser energy for $\mathrm{Q}=2 \times 10^{9} \mathrm{~s}^{-1}$ and $\mathrm{T}_{e q}=5000 \mathrm{~K}$

The least square method allows to plot the residue dependence as a function of temperatures; the residue is written :

$$
N\left(T_{j}\right)=\sum_{\lambda_{i}}\left[I_{\text {exp }}\left(\lambda_{i}\right)-I_{\text {calc }}^{T_{j}}\left(\lambda_{i}\right)\right]^{2}
$$

with $T_{j}$ the searched parameter. It shows that the accuracy is better at moderate temperatures. The uncertainty of the rotational temperature was estimated to $\pm 300 \mathrm{~K}$ in the free jet and $\pm 100 \mathrm{~K}$ within the boundary layer. Concerning the vibrational temperature, the uncertainty was never lower than $\pm 500 \mathrm{~K}$ in the free jet and $\pm 300 \mathrm{~K}$ within the boundary layer.

The calculations allowed to know how the fluorescence intensity varies with temperatures. For $T_{\text {vib }} \leq 6000 \mathrm{~K}$ and $T_{\text {rot }} \leq 3000 \mathrm{~K}$, this dependence can be considered 
as linear in spite of some saturated transitions. For higher temperature, lower state populations decrease and saturation effects are predominant. Since the fluorescence intensity is proportional to the density, the previous uncertainties on temperatures lead to a relative uncertainty on density close to $\pm 50 \%$ in the free jet and $\pm 30 \%$ within the boundary layer.

\section{Results}

Results were obtained both in the free jet and within the boundary layer above the flat plate. Two sections were explored in the free jet corresponding to distances equal to 50 and $100 \mathrm{~mm}$ from the quartz tube exit. This distance will be called $x$ in the following and $r$ will be the radial location. For the study within the boundary layer, the flat plate was located $80 \mathrm{~mm}$ upstream from the quartz tube exit. Measurements were made at distance equal to $15,20,25,30,40$ and $60 \mathrm{~mm}$ from the flat plate leading edge. This distance will be called $x^{\prime}$ in the following while $z$ will be the distance over the plate across the boundary layer. As a matter of interest, the coordinate systems were shown in figure 1.

\subsection{Free jet}

As shown in figure 10 , the vibrational temperature is about $5000 \pm 500 \mathrm{~K}$ at the center of the plasma jet for $x=100 \mathrm{~mm}$. This result is very close to that obtained by Raman

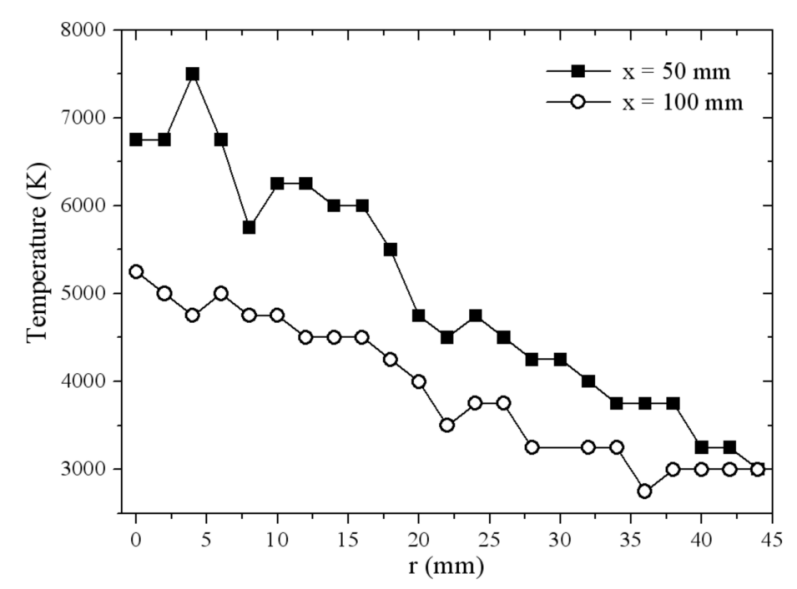

Figure 10. Vibrational temperatures radial profiles in the free jet

spectroscopy on $\mathrm{N}_{2}$ in the same conditions $(5400 \pm 200 \mathrm{~K})$ [19]. This is also true for the rotational temperature: we measured the rotational temperature of $\mathrm{NO}$ ground state equal to $2800 \pm 300 \mathrm{~K}$ for $x=100 \mathrm{~mm}$ while the rotational temperature of $\mathrm{N}_{2}$ ground state was found equal to $2800 \pm 400 \mathrm{~K}$ at the same location [19]. Nevertheless, the rotational temperature of $\mathrm{N}_{2}$ ground state was found to be quite constant along the jet axis between $x=80 \mathrm{~mm}$ and $x=120 \mathrm{~mm}$. The rotational temperature of NO ground 
state shows higher values at short distances since it is equal to $3700 \mathrm{~K}$ on the jet axis for $x=50 \mathrm{~mm}$ (Figure 11). No result concerning $\mathrm{O}_{2}$ is available because of the high dissociation degree in the free jet that prevented to carry out Raman scattering measurements with a sufficient accuracy.

The observed non-equilibrium is also a very interesting result: the rotational

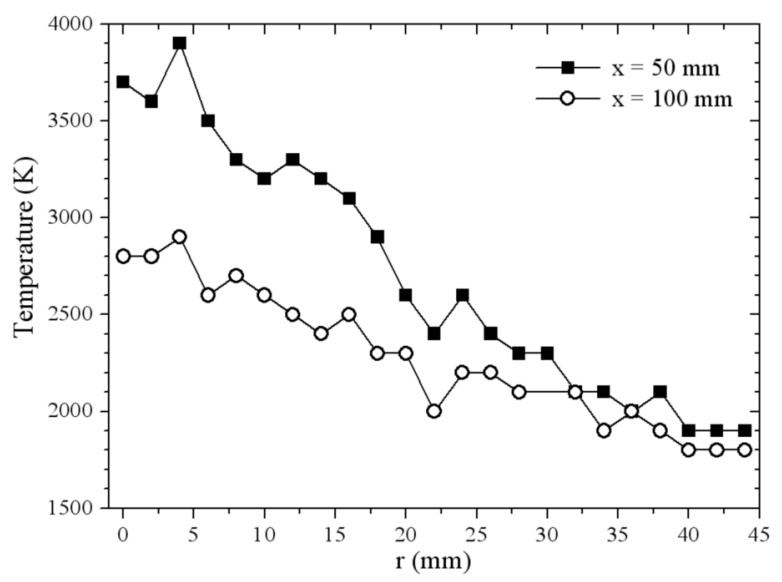

Figure 11. Rotational temperatures radial profiles in the free jet

temperatures are about half of the vibrational ones. The $\mathrm{N}_{2}$ and $\mathrm{NO}$ ground states have the same rotational temperature because the coupling with translation is efficient enough to ensure equilibrium in our conditions. Vibration-translation (VT) interactions are often supposed to be high enough on $\mathrm{NO}$ and $\mathrm{O}_{2}$ to suppose $T_{\text {vib }}=T_{\text {rot }}=T_{\text {trans }}$ for both species shortly downstream from the creation zone. Conversely, the $\mathrm{N}_{2}$ vibrational modes relaxation is not fast enough to obtain the same equality [33]. Our measurements show that vibrational and rotational temperatures are different for $\mathrm{N}_{2}$ and also for NO. Moreover in the free jet $\mathrm{N}_{2}$ and $\mathrm{NO}$ vibrational temperatures are found to be different. The inference to be drawn from this experimental result is that the vibrational energy equations for each molecule should be modeled separately.

The experimental NO density profiles and equilibrium density profiles for both studied sections are shown in figure 12. The NO density is radially constant in the center of the plasma free jet. This is true as the radius is less than about $15 \mathrm{~mm}$ at a distance $x=50 \mathrm{~mm}$ from the quartz tube exit. For $x=100 \mathrm{~mm}$, the uniform density zone is reduced to $5 \mathrm{~mm}$ from the axis.

The axial and radial profiles may be explained by temperature effects. The density increase along the axis corresponds to an observed temperature decrease from $x=50 \mathrm{~mm}$ to $x=100 \mathrm{~mm}$. The same decreases of rotational temperature as well as of vibrational temperature on the radial axis were measured (Figures 11 and 10 respectively). That yields an increasing NO ground state density from the center of the plasma jet to the boundary. On the boundary, the plasma is then mixed with steady air involving a decrease of NO density.

Some equilibrium calculations were carried out by minimizing the Gibbs enthalpy and 


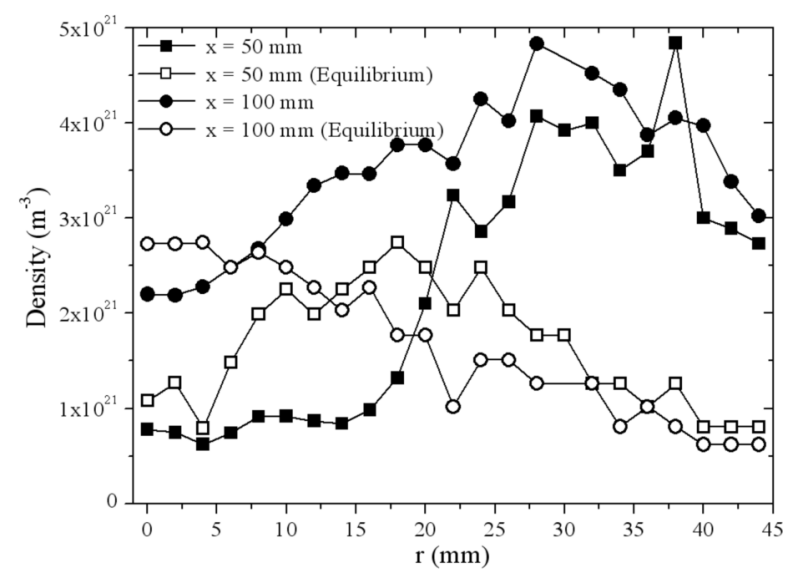

Figure 12. NO density radial profiles in the free jet compared with equilibrium values

by using the rotational temperature of the ground state as kinetic temperature. Those calculations are also reported in figure 12. We conclude that NO is close to chemical equilibrium at the centre of the free jet. Conversely, it withdraws from equilibrium along the jet radius where the aerodynamic characteristic time remains lower than the chemical characteristic time. For $x=50 \mathrm{~mm}$, the manifest increase of NO density for a radial position close to $20 \mathrm{~mm}$ corresponds to the edge of the plasma jet. Some changes in the temperature slope are also visible for this position in figures 10 and 11. Calculated densities are especially sensitive to the rotational temperature measurements which explains the small jump of calculated values.

\subsection{Boundary layer}

Figures 13 and 14 show that vibration and rotation remains out of equilibrium within the flat plate boundary layer. The non-equilibrium is however smaller close to the wall. This behaviour is similar to that observed on $\mathrm{N}_{2}$ and $\mathrm{O}_{2}$ by Raman spectroscopy [19]. As for $\mathrm{N}_{2}$ and $\mathrm{O}_{2}$, the characteristic lengths of profiles of vibrational and rotational temperatures over the flat plate are different. Another difference is the decrease of the rotational temperature along the axis. That is also verified for the limit rotational temperature outside the boundary layer. On the wall neither the rotational temperature nor the vibrational temperature seem to reach equilibrium. However we want to underline that the spatial resolution is not suitable with temperature gradients close to the wall. So results close to the wall are rough averages and cannot be considered as effective temperatures. Nevertheless, the non-equilibrium between vibration and rotation within the boundary layer suggests for a non-accommodation of vibrational temperature at the wall. Moreover, as in the free jet, the vibrational temperatures of the three majority species are different close to the wall. That may be true within the boundary layer but the differences between temperatures are lower than the uncertainty.

Unfortunately, density measurements are not accurate enough to estimate the bound- 
Demonstration of NO production in air plasma - metallic surface interaction by broadband laser-induced.

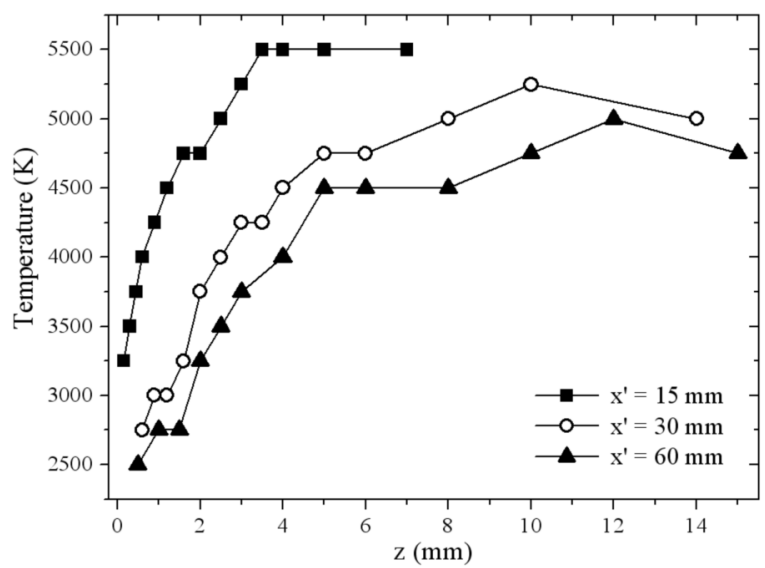

Figure 13. Vibrational temperatures vertical profiles within the boundary layer

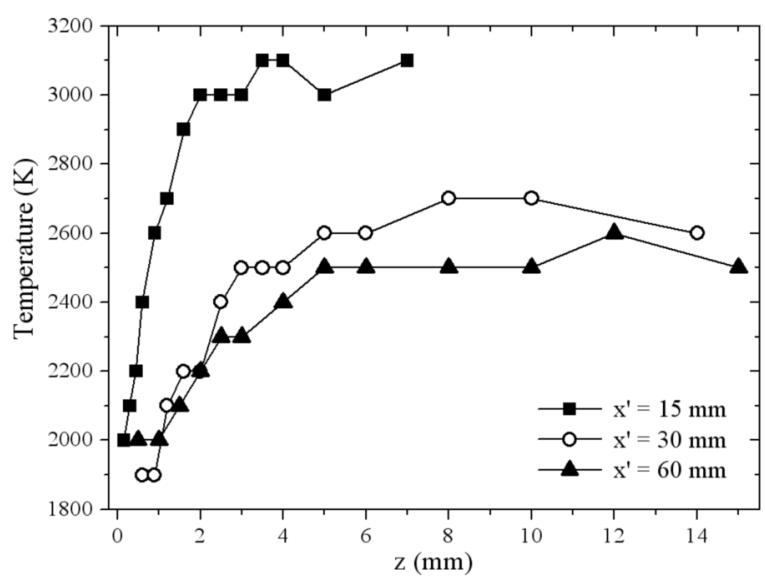

Figure 14. Rotational temperatures vertical profiles within the boundary layer

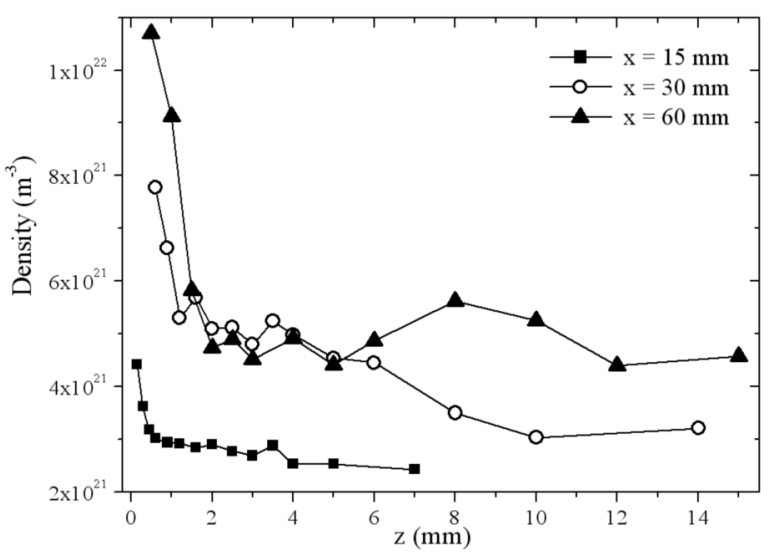

Figure 15. NO density vertical profiles within the boundary layer 
ary layer thickness for each section. Nevertheless, an obvious increase of NO density is observed close to the wall (Figure 15) whatever the distance to the leading edge og the plate. Moreover the NO density measured for $x^{\prime}=15 \mathrm{~mm}$ and $z=4 \mathrm{~mm}$ is similar to the value measured in the free jet i.e. $2 \times 10^{21} \mathrm{~m}^{-3}$. In the same way, the values obtained outside the boundary layer are close to those obtained in the free jet. For higher values of $x^{\prime}$, the boundary layer thickness is high enough to be disturbed by the non-homogeneous part of the free jet. Better results would have been obtained with a larger free jet and our configuration is an outcome of an estimate of the jet velocity based on temperatures measured by emission spectroscopy on $\gamma$ bands. Further investigations showed that the rotational temperature of the excited electronic state $A^{2} \Sigma^{+}$ of NO was different to the rotational temperature of the ground state [30].

\section{Discussion}

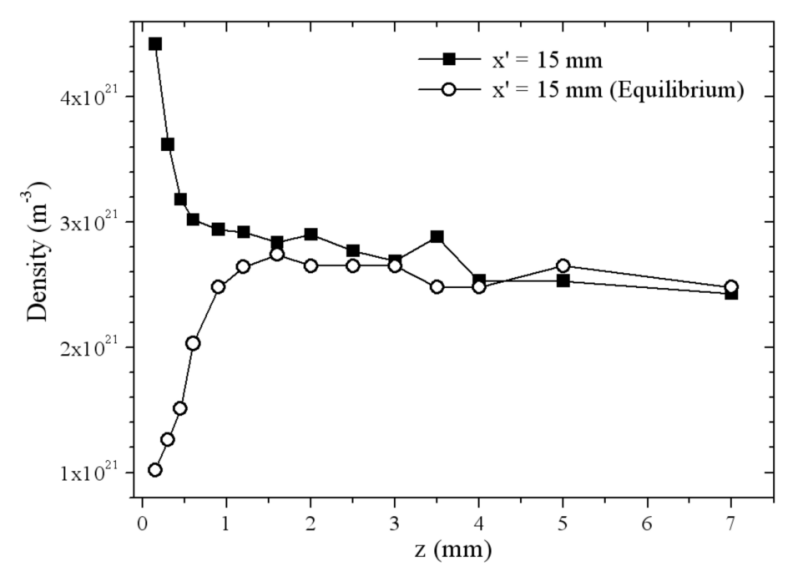

Figure 16. Comparison between experimental and equilibrium NO density vertical profiles within the boundary layer at $15 \mathrm{~mm}$ from the leading edge

The NO density increase close to the wall can be explained by a simple cooling effect due to the plate, a non-equilibrium production of NO in the boundary layer or a catalytic effect on the wall. In order to determine the respective contributions of those process, our group first calculated the equilibrium NO densities in the boundary layer. For those calculations, the equilibrium temperature has been taken equal to the measured NO ground state rotational temperature. Close to the leading edge $\left(x^{\prime}=15 \mathrm{~mm}\right)$, all the points outside the boundary layer may be considered in chemical equilibrium (Figure 16). That is in agreement with the free jet results presented in figure 12. Conversely, the difference between experimental and equilibrium NO densities becomes higher towards the wall where the NO equilibrium density is supposed to be very low. Further from the leading edge $\left(x^{\prime}=60 \mathrm{~mm}\right)$, the boundary layer is larger than the homogeneous plasma and the NO density is then out of equilibrium on the boundary of the jet because the 


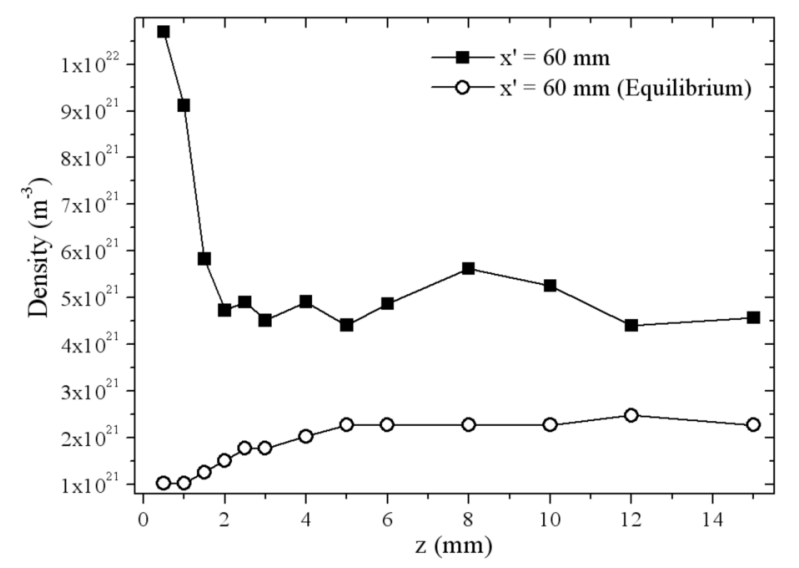

Figure 17. Comparison between experimental and equilibrium NO density vertical profiles within the boundary layer at $60 \mathrm{~mm}$ from the leading edge

boundary layer then interacts with the non-equilibrium part of the free jet (Figure 17). On the wall the NO density is increased by a factor $\approx 3$ where the equilibrium predict a negligible amount of $\mathrm{NO}$ at the wall temperature. A non-equilibrium effect is then responsible of the NO density increase within the boundary layer. A similar behavior should be observed whether the NO molar fraction was frozen from the free jet toward the wall. On the other hand, if some NO molecules are produced within the boundary layer or at the wall, the behavior of other species is important. $\mathrm{N}_{2}$ and $\mathrm{O}_{2}$ was previously measured [19] and those results are needed to analysis the NO production.

Figures 18, 19, and 20 present a comparison between the experimental density profiles,

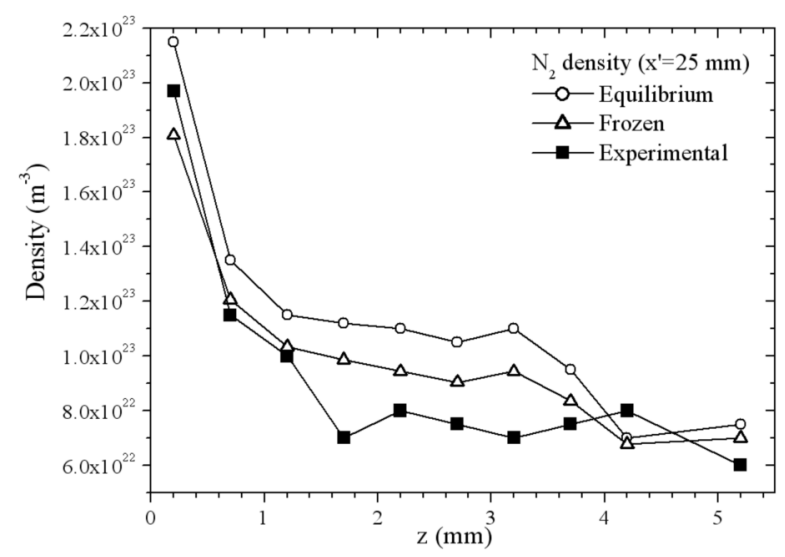

Figure 18. Comparison between experimental, frozen chemistry, and equilibrium $\mathrm{N}_{2}$ density vertical profiles within the boundary layer at $25 \mathrm{~mm}$ from the leading edge

the density profiles in the equilibrium hypothesis, and the density profiles in the frozen molar fraction hypothesis for $\mathrm{N}_{2}, \mathrm{O}_{2}$, and $\mathrm{NO}$ respectively. The results are presented for a distance to the leading edge $x^{\prime}=25 \mathrm{~mm}$ but the conclusions may be extrapoled 


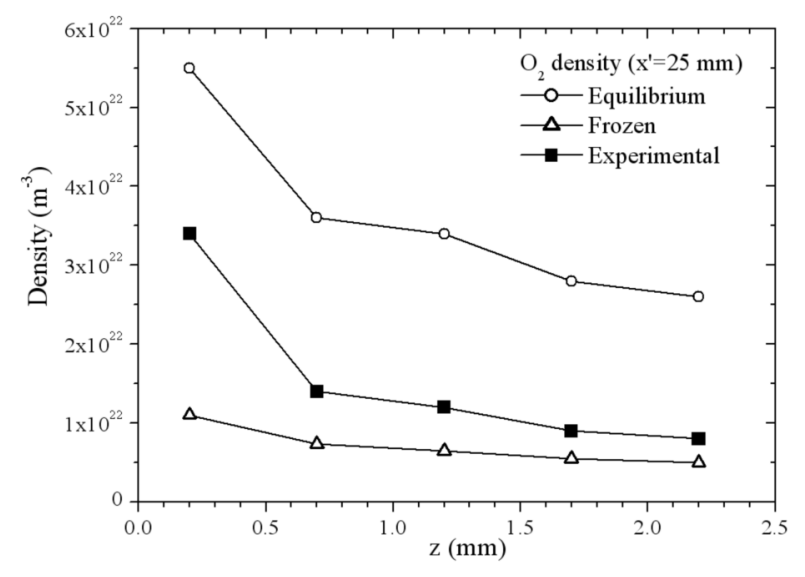

Figure 19. Comparison between experimental, frozen chemistry, and equilibrium $\mathrm{O}_{2}$ density vertical profiles within the boundary layer at $25 \mathrm{~mm}$ from the leading edge

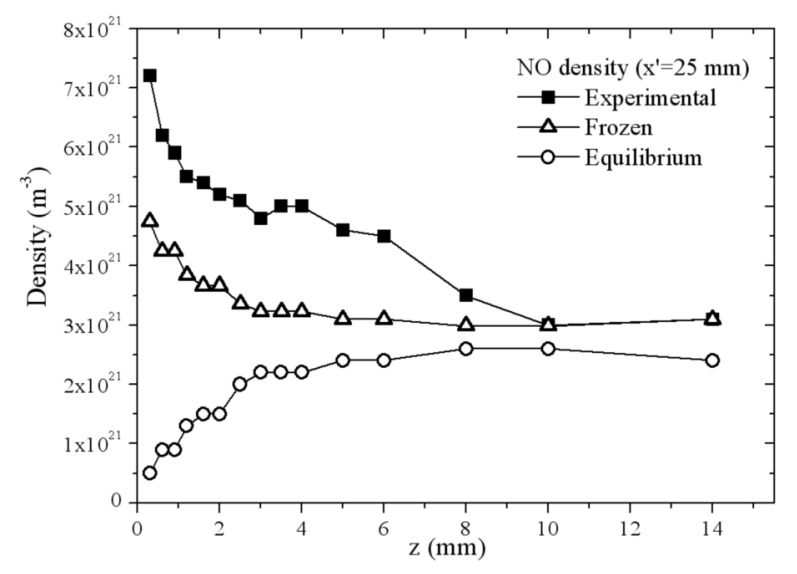

Figure 20. Comparison between experimental, frozen chemistry, and equilibrium NO density vertical profiles within the boundary layer at $25 \mathrm{~mm}$ from the leading edge

to any section while $x^{\prime}>10 \mathrm{~mm}$. The first millimetres following the leading edge are actually not sufficiently cooled to be sure that the surface is maintained to $300 \mathrm{~K}$ and the surface is coated with mullite. The densities in the frozen chemistry hypothesis are calculated assuming that the molar fraction is constant within the boundary layer and multiplying it by the ratio between the temperature outside the boundary layer and the temperature in the boundary layer. According to the uncertainty on density determination by Raman spectroscopy within the boundary layer (10\%), we may assert that the experimental $\mathrm{N}_{2}$ density profile is not different from the equilibrium density profile and from the density profile assuming a frozen $\mathrm{N}_{2}$ molar fraction (Figure 18). That means that the recombination of $\mathrm{N}_{2}$ within the boundary layer is low and cannot be detected by the measurement techniques used in the frame of this study. Only a direct measurement of atomic nitrogen density could allow to fix this issue. The conclusions are different for $\mathrm{O}_{2}$ (Figure 18). $\mathrm{O}_{2}$ densities are below the equilibrium values whatever 
the distance to the wall indicating a still high atomic oxygen density in the boundary layer (the NO density is too low to explain the departure from equilibrium). In fact, $\mathrm{O}_{2}$ chemistry is not far to be frozen in the main part of the boundary layer. The closest measurement to the wall $(z=0.2 \mathrm{~mm})$ indicates nevertheless an obvious increase of $\mathrm{O}_{2}$ density compared to the frozen hypothesis. The increasing $\mathrm{O}_{2}$ density, that is at least doubled at the wall, is the result of atomic oxygen recombination at the wall. Although the recombination appears to be important, it does not allow to reach the equilibrium density value. Concerning NO (Figure 20), there is also a clear departure between the experimental profile and the result of the frozen chemistry hypothesis. The NO density increase is then only weakly due to a temperature effect caused by the cooled plate but mainly to a production of NO. Considering than $\mathrm{O}_{2}$ and $\mathrm{N}_{2}$ chemistries are frozen in almost the whole boundary layer, $\mathrm{NO}$ should then be produced at the wall when $\mathrm{O}_{2}$ is recombined. A difference between both produced species is that the departure from the frozen chemistry hypothesis is observed far from the wall for NO. The explanation lies in a double formation of $\mathrm{NO}$ on the wall and in the gas phase.

In their modeling approach, Barbato and Bruno [35] underlined the role of catalycity and Zel'dovich reactions in NO production. The catalytic NO formation was detailed in one of their previous paper [36] in which a model predicts how $\mathrm{N}_{2}, \mathrm{O}_{2}$ and $\mathrm{NO}$ are produced on a surface through the four following equations :

$$
\begin{aligned}
& O(g)+O(a) \longrightarrow O_{2}(g) \\
& O(g)+N(a) \longrightarrow N O(g) \\
& N(g)+O(a) \longrightarrow N O(g) \\
& N(g)+N(a) \longrightarrow N_{2}(g)
\end{aligned}
$$

where $g$ stands for gaseous, and (a) stands for adsorbed. Nasuti et al.'s calculations confirm the lower recombination rate of $\mathrm{N}_{2}$ compared to $\mathrm{O}_{2}$. About $\mathrm{NO}$ creation at the wall, two mechanisms are possible but with a higher probability for reaction (2). In our study, atomic oxygen and atomic nitrogen densities are not measured but the measurements of molecular species densities, of temperature and simple mass conservation consideration can help us to obtain a rough estimation of those unknown densities. Considering the closest points to the wall $(0.3 \mathrm{~mm}),[\mathrm{N}]<0.2[\mathrm{O}]$ or $[\mathrm{N}]>[\mathrm{O}]$ are not conditions compatible with experimental observations. In any case, the atomic oxygen molar fraction remains close to 0.2 that makes it the second majority species after molecular nitrogen even close to the wall.

The recombination of oxygen at the wall and its diffusion away from the surface also induces NO formation through Zel'dovich reactions :

$$
\begin{aligned}
& \mathrm{N}_{2}+\mathrm{O}+3.32 \mathrm{eV} \rightleftharpoons \mathrm{NO}+\mathrm{N} \\
& \mathrm{O}_{2}+\mathrm{N} \rightleftharpoons \mathrm{NO}+\mathrm{O}+1.41 \mathrm{eV}
\end{aligned}
$$


Reaction rates of both reactions may be written :

$$
k=A T^{b} \exp \left(-\frac{T_{a}}{T}\right)
$$

Some constants for both forward and backward reactions are given in table 2 . In spite

\begin{tabular}{cccc}
\hline Reaction & $\mathrm{A}\left(\mathrm{m}^{3} \cdot \mathrm{s}^{-1}\right)$ & $\mathrm{b}$ & $\mathrm{T}_{a}(\mathrm{~K})$ \\
\hline $\mathrm{k}_{f,(5)}$ & $9.45 \times 10^{-18}$ & 0.42 & 42938 \\
\hline $\mathrm{k}_{f,(6)}$ & $4.14 \times 10^{-21}$ & 1.17938 & 4005.46 \\
\hline
\end{tabular}

Table 2. Kinetic constants for Zel'dovich reactions [37,38]

of the large densities of $\mathrm{N}_{2}$ and $\mathrm{O}$ in the boundary layer, the forward reaction (5) cannot play an important role because of its high activation threshold. Conversely the reverse reaction (5) cannot be neglected in the $\mathrm{NO}$ density balance since $\mathrm{N}_{2}$ recombination has been shown to be low. The resulting presence of atomic nitrogen is then favorable to the forward reaction (6) that releases energy in the boundary layer. For the moment, that exothermic feature could be a qualitative explanation for the quite large temperature measured close to the wall. Our measurements are then a confirmation of a double NO production at the wall through catalytic reactions and in the gas phase through Zel'dovich reactions following the diffusion of catalyticly produced $\mathrm{O}_{2}$.

Moreover, the second Zel'dovich reaction also depends on the wall catalycity. The more inert the wall is, the more negligible the equation (6) is. That last result was confirmed in works by Armenise et al. [39-42] thanks to a calculation taking into account a vibrational non-equilibrium for $\mathrm{N}_{2}$ and $\mathrm{O}_{2}$. Those works showed that heterogeneous recombination reactions leading to a NO production are of the utmost importance. They have also predicted a significant gap to Boltzmann distribution for vibrational levels of all species close to the wall. Unfortunately, only high vibrational levels (upper than 5) are sensitive to this effect and LIF (as well as Raman spectroscopy) gives data about only low vibrational levels. The agreement of our measurements with the model can also be illustrated by calculating the $\mathrm{NO}$ and $\mathrm{O}_{2}$ molar fractions. Figure 21 presents the molar fraction profiles above the flat plate for a distance $x^{\prime}=25 \mathrm{~mm}$ from the leading edge. Considering the uncertainty in temperature and pressure measurements, the final uncertainty on molar fraction cannot be lower than 20\%. While $\mathrm{O}_{2}$ molar fraction increases up to at least $0.2 \mathrm{~mm}$ to the surface, NO molar fraction is quite constant in the last $2 \mathrm{~mm}$. Those profile shapes are also in agreement with the plots shown in [35] for a finite catalytic rate surface and for a fully catalytic surface. The comparison remains qualitative because the aerodynamic conditions are very different between our experiment and Barbato and Bruno's calculations. Extrapolations of density and molar fraction profiles to the surface are not possible. First, they would lead to inconsistent values. Secondly, close to the wall, the large gradients become incompatible with the spatial resolution of the measurement technique.

The parallel configuration of the cooled metallic plate in the plasma jet allows to 


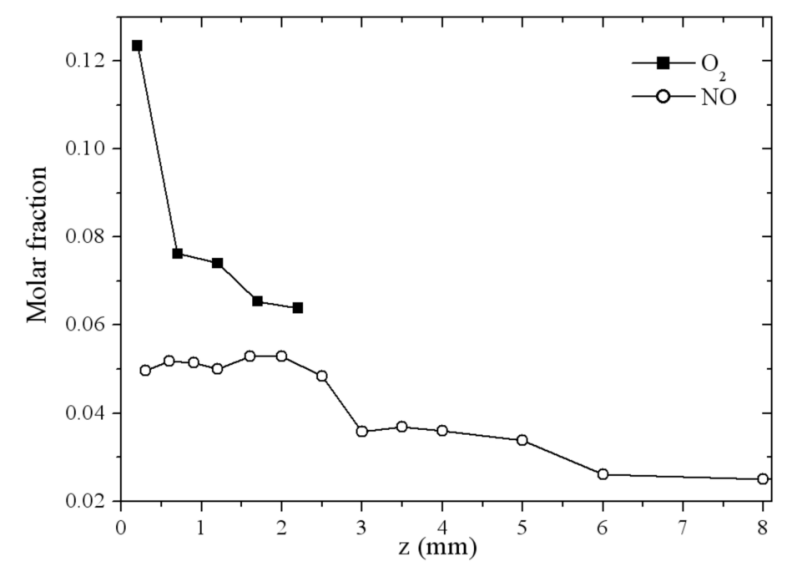

Figure 21. $\mathrm{O}_{2}$ and $\mathrm{NO}$ molar fractions profiles perpendicular to the metallic plate for $x^{\prime}=25 \mathrm{~mm}$

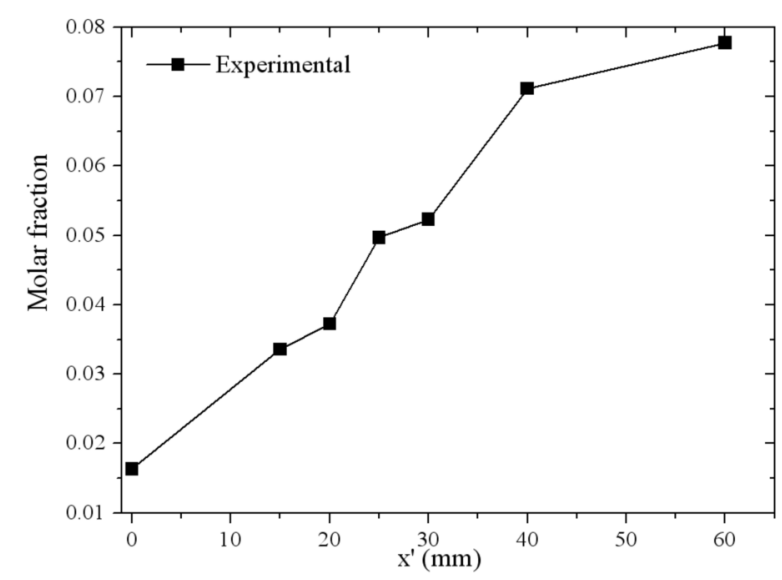

Figure 22. NO molar fraction along the main axis of the metallic flat plate for a distance to the surface equal to $0.3 \mathrm{~mm}$

control the temperature of the surface (at least sufficiently far from the leading edge) and to observe the development of physical and chemical processes in the boundary layer along the lengthwise axis of the plate. Figure 22 shows the profile of the measured NO molar fractions in the plasma flow direction $0.3 \mathrm{~mm}$ above the plate. The profile is a typical boundary layer profile. The part below $x^{\prime}=10 \mathrm{~mm}$ has to be carefully considered because of an uncontrolled cooling of the leading edge and its coating with mullite. This presentation is especially convenient for comparison with Navier-Stokes numerical calculations. Those necessary and complementary calculations presently in progress are not detailled in the frame of this paper.

The same approach can be used to compared how $\mathrm{N}_{2}, \mathrm{O}_{2}$ and $\mathrm{NO}$ molar fractions evolve from the leading edge to the far end of the matallic plate. Figure 23 show those profile on a normalized scale to allow an easy comparison. The densities at the leading edge 


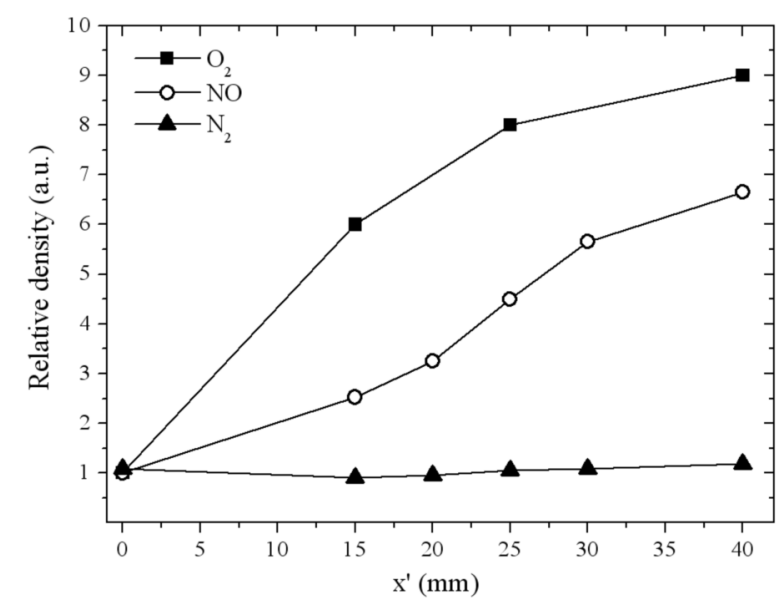

Figure 23. $\mathrm{O}_{2}, \mathrm{NO}$ and $\mathrm{N}_{2}$ relative molar fractions along the main axis of the metallic flat plate for a distance to the surface equal to $0.3 \mathrm{~mm}$

are $3.5 \times 10^{22} \mathrm{~m}^{-3}$ for $\mathrm{N}_{2}$, about $5 \times 10^{21} \mathrm{~m}^{-3}$ for $\mathrm{O}_{2}$ and $1.7 \times 10^{21} \mathrm{~m}^{-3}$ for NO. Those densities correspond to molar fractions equal to $0.41,0.06$ and 0.02 respectively with a relative uncertainty equal to $20 \%$. The presented measurements are taken at the closest points to the surface thus $0.3 \mathrm{~mm}$. Our results confirm that the $\mathrm{N}_{2}$ recombination is low on the metallic surface. Conversely, close to the surface $\mathrm{O}_{2}$ recombination is especially high even compared to the NO production at the wall. $\mathrm{O}_{2}$ recombination profile has a typical decreasing slope shape that should allow to derive interesting parameters about the surface chemistry by comparison with calculation. By moving from the surface to the border of the boundary layer, $\mathrm{N}_{2}$ relative molar fraction remain constant and $\mathrm{O}_{2}$ and NO curves get closer. For higher values of $z$, the relative increase of NO molar fraction becomes larger than $\mathrm{O}_{2}$ one as expected according to the double creation mode of NO molecules.

\section{Conclusion}

Some laser-induced fluorescence measurements were conducted on nitrogen monoxide using broadband laser excitation in an inductively coupled air plasma at moderate pressure. Vibrational and rotational temperatures as well as NO density were determined in the free jet and within the boundary layer above a flat metallic plate. The results complete and confirm some previous measurements made by Raman spectroscopy on $\mathrm{N}_{2}$ and $\mathrm{O}_{2}$ in the same plasma. An unexpected thermal non-equilibrium was identified on $\mathrm{NO}$ on the axis of the free jet and close to the wall inside the boundary layer which constitutes an important result in the frame of a physical vibration-translation modelling validation. We measured a large quenching rate on fluorescence decay that indicates the predominant role of an unexpected quencher excluding $\mathrm{N}_{2}, \mathrm{O}_{2}$ and $\mathrm{NO}$ supposed to be at equilibrium. The main result of this study is the evidence of NO production at the wall by a catalytic process and within the boundary layer through a Zel'dovich reaction 
following $\mathrm{O}_{2}$ recombination at the wall.

Those new results improve our understanding of high temperature air chemistry and then are a significant step towards the control of the entry of a spacecraft at high velocity in the atmosphere of Earth. Some complementary investigations should be conducted in the near future to finish the description of the species behaviour in the air plasma. Emission spectroscopy has already given some information about excited species populations. Atomic oxygen remains the last majority species unmeasured but accurate two-photon absorption laser-induced fluorescence (TALIF) measurements are still difficult in spite of progress on calibration methods. Last, electron densities and temperatures would be important data to record. Unfortunately, all attempts to perform Langmuir probe measurements with tungsten and iridium wires remains unsuccessful because of fast oxidation by atomic oxygen.

Following this study within the boundary layer of a metallic plate along the jet axis, a next step will be a similar study within the boundary layer of a $\mathrm{SiC}$ sample placed in front of the jet.

A numerical simulation using a Navier-Stokes code is also in progress out in order to reproduce the temperature and majority species profiles in the free jet. The code is also able to take into account the interaction of the plasma with the flat plate and to include parameters linked to the surface catalycity.

\section{Acknowledgments}

This work has been supported by the French space agency, the Centre National d'Etudes Spatiales (CNES), and the Centre National de la Recherche Scientifique (CNRS). The authors would like to thank Philippe Régnier and Arnaud Bultel for equilibrium chemistry calculations.

\section{References}

[1] Venkatapathy E, Laub B, Hartman G J, Arnold J O, Wright M J and Allen G A 2009 Adv. Space. Res. 441 138-150 doi:10.1016/j.asr.2008.12.023

[2] Pichon T, Barreteau R, Soyris P, Foucault A, Parenteau JM, Prel Y and Guedron S 2009 Acta Astronaut. 65 1-2 165-176 doi:10.1016/j.actaastro.2009.01.035

[3] Caogen Y, Hongjun L, Zhonghua J, Xinchao J, Yan L and Haigang Li 2008 Acta Astronaut. 63 1-4 280-284 doi:10.1016/j.actaastro.2007.12.059

[4] Singh H, Coburn J W and Graves D B 2000 J. Appl. Phys. 886 3748-3755 doi: 10.1063/1.1289046

[5] Seward W A and Jumper E J 1991 J. Thermophys. Heat Transfer 5 284-291 doi:10.2514/3.262

[6] Jumper E J and Seward W A 1994 J. Thermophys. Heat Transfer 8 460-465 doi:10.2514/3.565

[7] Kovalev V L and Kolesnikov A F 2005 Fluid Dynamics 495 669-693 doi:10.1007/s10697-005-0106-4

[8] Barbato M, Bruno C, Giordano D and Muylaert J 1996 J. Spacecraft Rockets 335 620-627 doi:10.2514/3.26811

[9] Kurotaki T 2001 J. Spacecraft Rockets 385 798-800 doi:10.2514/2.3749

[10] Pejaković D A, Marschall J, Duan L and Martin M P 2008 J. Thermophys. Heat Transfer 222 178-186 doi: 10.2514/1.33073

[11] McMillin B K, Lee M P and Hanson R K 1992 AIAA Journal 302 436-443 doi:10.2514/3.10935 
Demonstration of NO production in air plasma - metallic surface interaction by broadband laser-induced.

[12] Lee M P, McMillin B $\mathrm{K}$ and Hanson R $\mathrm{K} 1993$ Appl. Opt. $32 \quad 27$ 5379-5396 doi:10.1364/AO.32.005379

[13] Dankert C and Gundlach G 1991 Laser-induced fluorescence apparatus for application in rarefied hypersonic flow fields, DLR Report, Göttingen, Germany

[14] Robin L 2000 Measurement techniques for high enthalpy and plasma flows, RTO-EN-8 AC/323(AVT)TP/23, NATO Research and Technology Organisation, Neuilly-sur-Seine, France

[15] Boubert P, Chaix A, Robin L, Chikhaoui A and Vervisch P 2002 Shock Waves 115 341-351 doi:10.1007/s001930100117

[16] Schulz C, Sick V, Heinze J and Stricker W 1997 Appl. Opt. $36 \quad 15 \quad$ 3227-3232 doi:10.1364/AO.36.003227

[17] Herdrich G., Auweter-Kurtz M and Kurtz H 2000 J. Thermophys. Heat Transfer 142 244-249

[18] Chazot O, Krassilchikoff H W and Thmel J 2008 AIAA Paper 2008-1252

[19] Studer D and Vervisch P 2007 J. Appl. Phys. 1023033303 doi:10.1063/1.2768067

[20] Danielak J, Domin U, Kępa R, Rytel M and Zachwieja M 1997 J. Mol. Spectrosc. 1812 394-402 doi:10.1006/jmsp.1996.7181

[21] Amiot C 1982 J. Mol. Spectrosc. 941 150-172 doi:10.1016/0022-2852(82)90301-0

[22] Kovács I 1969 Rotational structure in the spectra of diatomic molecules, Adam Hilger LTD, London, United Kingdom

[23] Lino da Silva M 2004 Simulation des propriétés radiatives du plasma entourant un vhicule traversant une atmosphre plantaire vitesse hypersonique, $\mathrm{PhD}$ Thesis, Orléans, France

[24] Laux C O and Kruger C H 1992 J. Quant. Spectrosc. Radiat. Transfer 481 9-24 doi:10.1016/00224073(92)90003-M

[25] Luque J and Crosley D R 1999 J. Chem. Phys. 11116 7405-7415 doi:10.1063/1.480064

[26] Thoman J W, Gray J A, Durant J L and Paul P H 1992 J. Chem. Phys. 9711 8156-8163 doi:10.1063/1.463437

[27] Cattolica R, Mataga T and Cavolowsky J 1989 J. Quant. Spectrosc. Radiat. Transfer 426 499-508 doi:10.1016/0022-4073(89)90040-X

[28] Lee S, Luque J, Reppel J, Brown A and Crosley D R 2004 J. Chem. Phys. 1213 1373-1382 doi: $10.1063 / 1.1756868$

[29] Naik S V and Laurendeau N M 2004 Appl. Phys. B 795 641-651 doi:10.1007/s00340-004-1604-5

[30] Studer D, Boubert P and Vervisch P 2010 To be published

[31] Boubert P 1999 Méthodes spectroscopiques appliquées aux plasmas et aux milieux haute enthalpie, PhD Thesis, Rouen, France

[32] Eckbreth A 1988 Laser diagnostics for combustion temperature and species, Abacus Press, Tunbridge Welles, United Kingdom

[33] Park C 1990 Nonequilibrium hypersonic aerodynamics, John Wiley \& Sons, New York, USA

[34] Honoré D 1995 Fluorescence induite par laser excimères bande-fine. Application la caractérisation de souffleries hautes enthalpies, $\mathrm{PhD}$ Thesis, Rouen, France

[35] Barbato M and Bruno C 1996 Molecular Physics and Hypersonics Flows, Mario Capitelli, NATO ASI Series C482 139-160

[36] Nasuti F, Barbato M and Bruno C 1996 J. Thermophys. Heat Transfer 101 131-136

[37] Bose D and Candler G V 1996 J. Chem. Phys. 1048 2825-2833 doi:10.1063/1.471106

[38] Bose D and Candler G V 1997 J. Chem. Phys. 10716 6136-6145 doi:10.1063/1.475132

[39] Capitelli M, Armenise I and Gorse C 1997 J. Thermophys. Heat Transfer 114 570-578 doi: $10.2514 / 2.6281$

[40] Armenise I, Capitelli M, Gorse C, Cacciatore M and Rutigliano M 2000 J. Spacecraft Rockets 37 3 318-323 doi:10.2514/2.3581

[41] Armenise I, Capitelli M and Gorse C 2001 J. Spacecraft Rockets 384 482-487 doi:10.2514/2.3730

[42] Armenise I and Capitelli M 2005 Plasma Sources Sci. Technol. 142 S9-S17 doi:10.1088/0963$0252 / 14 / 2 / \mathrm{S} 02$ 